\title{
Influência da monensina sódica no consumo e na digestibilidade de dietas com diferentes teores de proteína para ovinos ${ }^{1}$
}

\section{Marcus Vinícius Morais de Oliveira ${ }^{2}$, Rogério de Paula Lana ${ }^{3}$, Eduardo da Costa Eifert ${ }^{4}$, Dirce Ferreira Luz ${ }^{2}$, José Carlos Pereira ${ }^{3}$, Juan Ramón Olalquiaga Pérez ${ }^{5}$, Fernando Miranda de Vargas Junior 6}

\author{
1 Parte da tese de Doutorado do primeiro autor apresentada à UFV. \\ 2 Unidade Universitária de Aquidauana - Universidade Estadual de Mato Grosso do Sul. \\ ${ }^{3}$ Departamento de Zootecnia - Universidade Federal de Viçosa. \\ ${ }^{4}$ Embrapa Arroz e Feijão. \\ ${ }^{5}$ Departamento de Zootecnia - Universidade Federal de Lavras. \\ ${ }^{6}$ Curso de Medicina Veterinária - Universidade para o Desenvolvimento do Estado e da Região do Pantanal.
}

RESUMO - Foram alojados 25 ovinos castrados em gaiolas para estudos de metabolismo por 20 dias com o objetivo de determinar a influência da monensina na digestibilidade de dietas formuladas com diferentes teores de proteína. As dietas foram compostas de 11,4 e $16,5 \%$ de PB na MS, sendo constituídas de $65 \%$ de feno de capim-braquiária (Brachiaria decumbens) e $35 \%$ de concentrado, com inclusão ou não de $28 \mathrm{mg}$ de monensina/kg de MS consumida, totalizando quatro dietas experimentais e uma composta apenas de feno puro. O concentrado da dieta com menor teor protéico era à base de milho e uréia e o da dieta com maior teor protéico, à base de milho e farelo de soja. Utilizou-se um delineamento em blocos casualizados, em que as dietas foram avaliadas por contrastes ortogonais completos. A inclusão de monensina na dieta reduziu significativamente os consumos de MS, MO, PB, EE, carboidratos totais (CT), FDN e NDT, porém, não afetou a digestibilidade. A monensina também reduziu a perda de nitrogênio pelas fezes; no entanto, a maior retenção de nitrogênio ocorreu nos animais que não receberam monensina na dieta. O nível de proteína influenciou significativamente os consumos de PB, EE e CT, sendo observado maior consumo de proteína, lipídios e carboidratos nas dietas com alto e baixo teor protéico, respectivamente. O nível de proteína não influenciou a digestibilidade dos nutrientes, à exceção da PB e do EE, para os quais a digestibilidade foi maior nos animais que consumiram dietas com alto e baixo teor protéico, respectivamente. A dieta contendo apenas feno de capim-braquiária foi menos consumida e apresentou menor digestibilidade e balanço de nitrogênio negativo.

Palavras-chave: gaiola para estudos de metabolismo, ionóforos, ruminantes

\section{Effect of monensin on intake and apparent digestibility of nutrients in sheep fed diets with different crude protein levels}

\begin{abstract}
The objective of this trial was to evaluate the effect of monensin in the apparent digestibility of nutrients in diets with different levels of CP. Twenty-five castrated rams were housed in metabolism cages for 20 days and fed diets with 11.4 or $16.5 \%$ of CP (\% DM) supplemented or not with $28 \mathrm{mg}$ of monensin $/ \mathrm{kg}$ of DM. Diets contained $65 \%$ of signalgrass hay (Brachiaria decumbens) and 35\% of concentrate; a diet containing only signal grass hay was also fed. The concentrate of diets with $11.4 \% \mathrm{CP}$ was composed by corn and urea while that of diets with $16.5 \% \mathrm{CP}$ was based on corn and soybean meal. A completely randomized block design was used and treatment differences were separated by complete orthogonal contrasts. Although monensin significantly reduced the intakes of DM, OM, CP, EE, TC, NDF and TDN, no differences were observed for apparent digestibility of nutrients. Monensin also reduced fecal excretion of $\mathrm{N}$ but the greatest $\mathrm{N}$ retention was observed in animals fed diets with no supplementation. Diets with the highest CP levels also had the highest CP intake while those with the lowest CP levels showed greatest intakes of EE and TC. Dietary CP level had no significant effect on nutrient digestibility with the exception of $\mathrm{CP}$ and EE, which were higher on animals fed diets with high and low CP contents, respectively. The diet containing only signalgrass hay resulted in the lowest intake and digestibility of nutrients and also led to a negative $\mathrm{N}$ balance.
\end{abstract}

Key Words: ionophore, metabolism cage, ram, ruminant

\section{Introdução}

O ponto de partida para avaliação da qualidade nutricional de uma dieta são as análises bromatológicas, pelas quais se determina a composição química dos alimentos. Todavia, somente esta informação não é suficiente para assegurar que o desempenho dos animais que receberão esses alimentos seja condizente com o desempenho 
estimada, pois, em muitos casos, os nutrientes estão presentes no alimento, mas indisponíveis para o animal. Desse modo, também é necessário saber sua digestibilidade, ou seja, determinar a fração do alimento que realmente está disponível para o animal. Segundo Schneider \& Flatt (1975), a determinação da digestibilidade de um alimento inclui uma medida quantitativa dos nutrientes consumidos e das quantidades excretadas nas fezes, sendo, portanto, definida como a fração do nutriente ingerido que não é recuperada nas fezes.

À exceção dos carboidratos da parede celular, o coeficiente de digestibilidade normalmente é determinado na forma aparente; ou seja, nas fezes não são separadas a fração indigerível do alimento das substâncias endógenas do próprio animal, que são liberadas no trato digestivo na forma de enzimas, mucinas, descamações da mucosa epitelial, entre outros, subestimando a digestibilidade verdadeira ou real (Andriguetto et al., 1981). O nível de ingestão dos alimentos e, conseqüentemente, a taxa de passagem influenciam a digestibilidade de modo preponderante. Esses fatores dependem da espécie e idade do animal, do processamento e da composição química dos alimentos, da inclusão de aditivos na ração, da temperatura ambiente e da disponibilidade de água (Silva \& Leão, 1979).

De acordo com Maynard et al. (1984), o aumento do consumo de alimentos a partir de determinado nível diminui a digestibilidade da ração, mas melhora o desempenho do animal, em decorrência da maior quantidade de nutrientes disponíveis. A máxima digestibilidade da ração ocorre quando o alimento permanece maior tempo no trato gastrintestinal, o que pode ser observado quando há menor nível de ingestão, porém, nesses casos, o desempenho do animal é comprometido.

Como os ionóforos reduzem o consumo de alimentos, espera-se que a inclusão de monensina sódica à dieta proporcione, do mesmo modo, aumento na digestibilidade da dieta (Wedegaertner \& Johnson, 1983; Medel et al., 1991; McGuffey et al., 2001). Ionóforos, como a monensina sódica, são substâncias produzidas principalmente por cepas de Streptomyces cinnamonensis (Haney \& Hoehn, 1967), que agem de forma análoga aos antibióticos, graças à sua capacidade inibidora sobre bactérias gram-positivas (Teather \& Forster, 1998).

Esse efeito decorre da própria estrutura química da molécula de monensina, que, sendo altamente lipofílica e com aptidão para se ligar a prótons, adere à membrana celular externa das bactérias, que são ricas em lipídios, catalisando a entrada ou saída de determinados íons (Russell, 1996). Inicialmente, ocorre elevada saída de $\mathrm{K}^{+} \mathrm{e}$ entrada de $\mathrm{H}^{+}$para dentro da célula, causando redução do $\mathrm{pH}$. A célula reage para estabilizar o pH e o balanço iônico celular, exportando $\mathrm{H}^{+}$para o meio por intermédio das bombas de $\mathrm{Na}^{+} / \mathrm{K}^{+}$e de próton ATPase. Como o gasto energético é muito elevado, com o passar do tempo, as bactérias morrem ou assumem um nicho microbiano sem expressão ruminal (Russell \& Strobel, 1989). De acordo com Russell \& Wallace (1997), as bactérias gram-negativas não sofrem os efeitos da ação dos ionóforos, pois possuem dupla membrana celular, de modo que a membrana interna permanece protegida da ação da monensina. Como protozoários e fungos não possuem membrana protetora externa, também são sensíveis à monensina (Dennis et al., 1986).

Outro aspecto importante é que os produtos finais da fermentação dos alimentos no rúmen pelas bactérias gramnegativas são os ácidos propiônico e succínico; os das bactérias gram-positivas são os ácidos acético e butírico e, de forma indireta, os gases metano e o dióxido de carbono; de amônia e do ácido láctico (Russell \& Wallace, 1997). Portanto, a inclusão de monensina promove no ambiente ruminal aumento da concentração molar do ácido propiônico, concomitantemente com redução dos ácidos acético, butírico e láctico e dos gases metano, dióxido de carbono e amônia (Machado \& Madeira, 1990). A menor fermentação de aminoácidos dietéticos no rúmen é compensada pelo seu maior aproveitamento no intestino delgado (Medel et al., 1991).

Os mecanismos pelos quais a monensina promove redução do consumo ainda não estão totalmente esclarecidos, no entanto, a menor ingestão de alimentos está mais correlacionada ao aumento da energia líquida da dieta, que depende diretamente da mudança de perfil dos ácidos graxos voláteis gerados no rúmen-retículo e do aumento do aporte de aminoácidos de origem alimentar potencialmente digeríveis no intestino delgado (Hanson \& Klopfenstein, 1979; Byers, 1980; Fox \& Black, 1984; Clary et al., 1993). A ação dos ionóforos sobre a flora ruminal e, consequientemente, nos produtos gerados com a fermentação de alimentos é bastante conhecida (Galyean \& Owens, 1988; Kalachnyuk et al., 1990; Yang \& Russell, 1993; Andrae et al., 1995; Granzin \& Dryden, 1999; Oliveira et al., 2002). Entretanto, a influência da monensina na digestibilidade dos alimentos tem sido pouco pesquisada.

Desse modo, verificou-se neste experimento a influência da monensina sódica sobre a digestibilidade de dietas contendo diferentes níveis de proteína para ovinos.

\section{Material e Métodos}

O ensaio foi conduzido no Setor de Nutrição Animal pertencente ao Departamento de Zootecnia da Universidade 
Federal de Viçosa, em Viçosa - MG. Foram utilizados 25 cordeiros castrados, mestiços Bergamácia $\times$ Santa Inês, e com peso vivo médio de $49,3 \mathrm{~kg}$. No período pré-experimental, os animais foram pesados em jejum de sólidos (12 horas) e distribuídos em blocos de acordo com o peso vivo. Posteriormente, foram mantidos alojados em galpão de alvenaria, presos em gaiolas para estudos de metabolismo confeccionadas em aço e equipadas com coletor de urina, cocho para alimento e bebedouro. Como na gaiola não havia coletor de fezes, a coleta foi feita utilizando-se bolsa coletora de lona, revestida internamente com napa e presa ao animal por meio de arreio. No período pré-experimental, todos os animais foram tratados contra ecto e endoparasitos para controle das infestações por parasitos externos e internos.

$\mathrm{O}$ experimento teve duração de 20 dias: 15 para a adaptação dos animais às instalações, ao manejo e ao alimento e cinco para determinação da digestibilidade e do balanço de nitrogênio.

As dietas experimentais foram formuladas para conter 11,4 e $16,5 \%$ de PB na MS, sendo constituídas de $65 \%$ de feno de capim-braquiária (Brachiaria decumbens) e 35\% de concentrado, com inclusão ou não de $28 \mathrm{mg}$ de monensina/kg de MS consumida, além de uma dieta contendo apenas feno. O concentrado das dietas com baixo teor protéico foi formulado à base de milho e uréia, enquanto o das dietas com alto teor protéico foi composto de milho e farelo de soja (Tabela 1). As dietas foram fornecidas à vontade, duas vezes ao dia, em duas partes iguais, às $8 \mathrm{e}$ às $17 \mathrm{~h}$. O Rumensin ${ }^{\circledR}$ foi incluído no concentrado diariamente, de forma parcelada, na proporção de $0,33 \mathrm{~g} / \mathrm{kgMS}$, correspondendo às dietas com $28 \mathrm{mg}$ de monensina/kg MS consumida.

Tanto os alimentos oferecidos como as sobras foram coletados, pesados e amostrados diariamente, pela manhã, durante todo o período experimental. A coleta, a pesagem e a amostragem das fezes (10\% do total excretado após homogeneização), no entanto, foram feitas duas vezes ao dia, às $7 \mathrm{~h}$ e às $17 \mathrm{~h}$. A urina, após filtragem em tela de náilon, foi coletada em balde contendo $100 \mathrm{~mL}$ de ácido sulfúrico a 30\%, para diminuir o pH e preservar a composição química, evitando as perdas de nitrogênio (amônia) por volatilização. O volume de urina foi medido com uma proveta de $2.000 \mathrm{~mL}$ e amostrado ( $3 \%$ do volume total) uma única vez ao dia, às $9 \mathrm{~h}$. Todas as amostras foram devidamente identificadas e congeladas em freezer, efetuando-se, ao final do ensaio, uma amostra composta do período (cinco dias) por animal.

Ao final do experimento, as amostras do alimento fornecido, das sobras e das fezes foram descongeladas em temperatura ambiente, secas em estufa de ventilação forçada a $65^{\circ} \mathrm{C}$ por 72 horas e processadas em moinho do tipo Willey
Tabela 1 - Composição percentual dos ingredientes e teores de PB e NDT das dietas com baixo e com alto teor protéico, \% da MS 1

Table 1 - Ingredient and chemical composition of diets with different $C P$ levels, \% DM

\begin{tabular}{|c|c|c|}
\hline \multirow[t]{2}{*}{$\begin{array}{l}\text { Ingrediente } \\
\text { Ingredient }\end{array}$} & \multicolumn{2}{|c|}{$\begin{array}{l}\text { Teor protéico } \\
\text { Protein content }\end{array}$} \\
\hline & $\begin{array}{l}\text { Baixo } \\
\text { Low }\end{array}$ & $\begin{array}{l}\text { Alto } \\
\text { High }\end{array}$ \\
\hline $\begin{array}{l}\text { Feno de capim-braquiária }(\%) \\
\text { Signalgrass hay (\%) }\end{array}$ & 65,11 & 65,00 \\
\hline $\begin{array}{l}\text { Milho grão }(\%) \\
\text { Corn grain }(\%)\end{array}$ & 33,25 & 14,70 \\
\hline $\begin{array}{l}\text { Uréia }(\%) \\
\text { Urea }(\%)\end{array}$ & 0,91 & - \\
\hline $\begin{array}{l}\text { Sulfato de amônia (\%) } \\
\text { Ammonium sulfate (\%) }\end{array}$ & 0,09 & - \\
\hline $\begin{array}{l}\text { Farelo de soja }(\%) \\
\text { Soybean meal }(\%)\end{array}$ & - & 20,0 \\
\hline $\begin{array}{l}\text { Mistura mineral }(\%)^{2} \\
\text { Mineral mixture }(\%)\end{array}$ & 0,64 & 0,33 \\
\hline $\begin{array}{l}\text { Total }(\%) \\
\text { Total (\%) }\end{array}$ & 100,00 & 100,00 \\
\hline $\begin{array}{l}\mathrm{PB}(\% \text { na } \mathrm{MS}) \\
C P(\% \text { of } D M)\end{array}$ & 11,45 & 16,54 \\
\hline $\begin{array}{l}\text { NDT (\% na MS) } \\
\text { TDN (\% of DM) }\end{array}$ & 64,26 & 66,26 \\
\hline 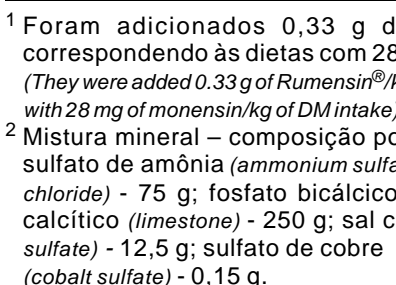 & $\begin{array}{l}\text { mensin }{ }^{\circledR / /} \\
\text { e monensir } \\
\text { 1offered, cor } \\
\text { Mineral mixt } \\
5 \mathrm{~g} \text {; cloret } \\
\text { Icium phosp } \\
\text { (salt) - } 85 \\
\text { r sulfate) - } 2\end{array}$ & $\begin{array}{l}\text { oferecida, } \\
\text { S consumida } \\
\text { othe treatments } \\
\text { osition per } \mathrm{kg} \text { ): } \\
\text { sio (potassium } \\
5 \mathrm{~g} \text {; calcário } \\
\text { de zinco (zinc } \\
\text { to de cobalto }\end{array}$ \\
\hline
\end{tabular}

Tabela 2 - Composição bromatológica do feno de capimbraquiária (Brachiaria decumbens) e do concentrado forecidos aos animais

Table 2 - Chemical composition of signalgrass hay (Brachiaria decumbens) and concentrate fed to animals

\begin{tabular}{|c|c|c|c|c|c|c|c|}
\hline \multirow[t]{3}{*}{ Item } & \multirow[t]{3}{*}{$\begin{array}{l}\text { MS - \% } \\
D M-\%\end{array}$} & \multicolumn{6}{|c|}{$\begin{array}{l}\% \text { na MS } \\
\% \text { of } D M\end{array}$} \\
\hline & & $\mathrm{MO}$ & PB & EE & $\mathrm{CT}$ & FDN & FDA \\
\hline & & $O M$ & $C P$ & $E E$ & $T C$ & $N D F$ & $A D F$ \\
\hline
\end{tabular}

Feno braquiária $\quad 86,06 \quad 93,96 \quad 7,90 \quad 0,90 \quad 85,16 \quad 77,72 \quad 45,65$ Signalgrass hay

Concentrado

Concentrate

\begin{tabular}{llllllll}
\hline $\begin{array}{l}\text { Baixo teor } \\
\text { protéico }\end{array}$ & 86,99 & 97,25 & 17,06 & 4,36 & 75,83 & 13,29 & 4,05 \\
$\begin{array}{l}\text { Low protein content } \\
\text { Alto teor }\end{array}$ & 87,90 & 95,13 & 32,26 & 3,16 & 59,70 & 12,98 & 7,36 \\
protéico & & & & & & & \\
High protein content
\end{tabular}

com peneira de malha de $1 \mathrm{~mm}$. Posteriormente, realizaram-se análises para determinação dos teores de MS, MO, PB, EE, FDN, FDA e cinzas, segundo metodologia descrita por Silva (1990). Os carboidratos totais (CT) foram determinados pela 
equação: $\mathrm{CT}=\{100-[\mathrm{PB}(\% \mathrm{MS})+\mathrm{EE}(\% \mathrm{MS})+$ Cinzas $(\% \mathrm{MS})]\}$; e os teores de NDT foram calculados pela equação: $\mathrm{NDT}(\mathrm{g} / \mathrm{dia})=\{(\mathrm{PB}$ ingerida $-\mathrm{PB}$ fezes $)+(\mathrm{CT}$ ingerido - CT fezes $)+[2,25 *$ (EE ingerido - EE fezes $)]\}$, proposta por Sniffen et al. (1992). Na Tabela 2 são apresentadas as composições bromatológicas do feno de capim-braquiária e do concentrado fornecidos aos animais.

O delineamento utilizado foi em blocos casualizados com cinco tratamentos (dietas) e cinco repetições, sendo os tratamentos avaliados por contrastes ortogonais completos, a 5\% de probabilidade, pelo programa SAS (1997).

\section{Resultados e Discussão}

Neste experimento, o nível de proteína influenciou significativamente os consumos de PB, EE e CT (Tabela 3), observando-se maior consumo de proteína, lipídios e carboidratos nas dietas com alto e baixo teor protéico, respectivamente (Tabela 4). O fornecimento de monensina promoveu redução significativa em todas as variáveis, ou seja, nos consumos de MS, MO, PB, EE, CT, FDN e NDT (Tabelas 3 e 4), mas não foi verificada, entretanto, interação teor protéico $\times$ monensina (Tabela 3 ). Os animais que receberam somente feno de capim-braquiária apresentaram menores consumos de MS, MO, PB, EE e NDT e consumos semelhantes de FDN (Tabelas 3 e 4).

Possivelmente, a redução no consumo dos nutrientes da dieta contendo ionóforo foi ocasionada pelo maior aporte de energia via aumento da concentração de succinato do tecido hepático do animal, o que está relacionado à mudança no perfil microbiano no ambiente ruminal, decorrente do aumento das bactérias gram-negativas em detrimento das gram-positivas, com conseqüente alteração na concentração dos ácidos graxos voláteis, ou seja, com elevação da concentração dos ácidos propiônico e butírico em relação ao ácido acético. De modo semelhante, Medel et al. (1991) também verificaram que o fornecimento de monensina a bovinos em confinamento promoveu diminuição no consumo sem alterar o ganho de peso, ocasionando, portanto, redução na conversão alimentar. Esse menor consumo está relacionado também às mudanças no metabolismo energético e ao maior aporte de aminoácidos dietéticos no intestino delgado, em decorrência da diminuição da deaminação da proteína no rúmen.

Todavia, Ward et al. (1990a,b), ao fornecerem monensina a novilhos com cânula ruminal mantidos em pastagem nativa no verão e no inverno, respectivamente, não observaram alterações significativas no consumo de forragem. No entanto, verificaram redução no enchimento do trato gastrintestinal. Utilizando novilhos em confinamento,

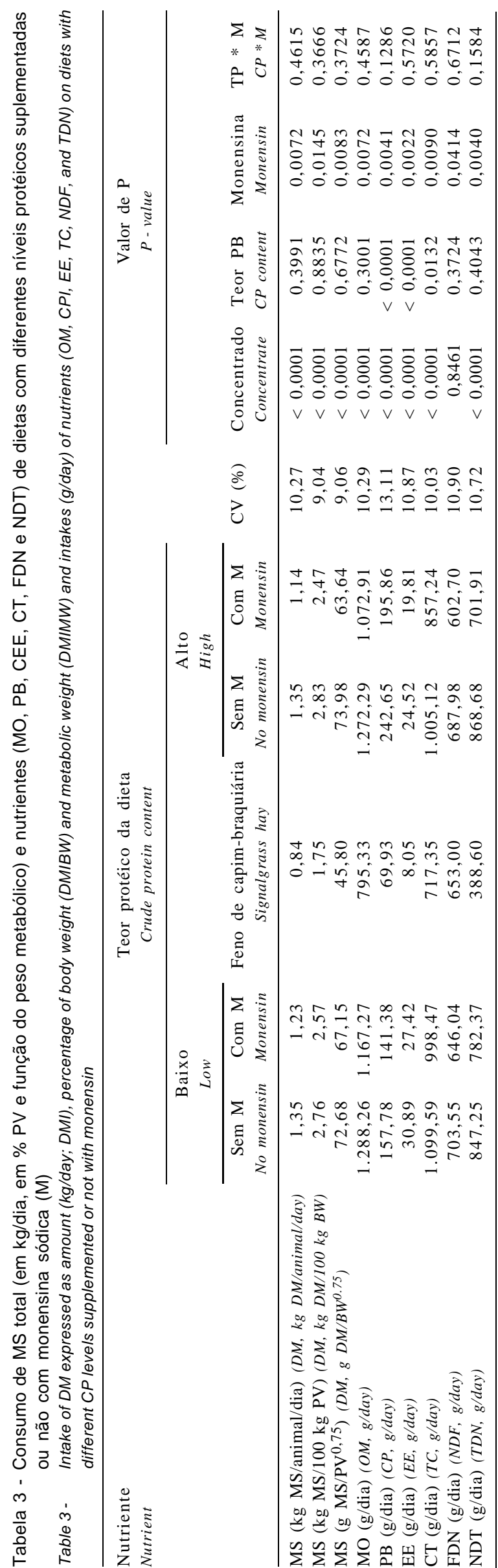

(c) 2007 Sociedade Brasileira de Zootecnia 
Tabela 4 - Consumo de MS (em kg/dia, em \%PV e em função do peso metabólico) e de nutrientes (MO, PB, EE, CT, FDN e NDT) de dietas com diferentes níveis protéicos suplementadas ou não com monensina sódica

Table 4 - Intakes of DM expressed as amount (kg/day; DMI), percentage of body weight (DMIBW) and metabolic weight (DMIMW) and intakes ( $\mathrm{g} /$ day) of nutrients (OM, CPI, EE, TC, NDF, and TDN) on diets with different CP levels supplemented or not with monensin

\begin{tabular}{|c|c|c|c|c|c|c|}
\hline \multirow[t]{2}{*}{$\begin{array}{l}\text { Nutriente } \\
\text { Nutrient }\end{array}$} & \multicolumn{2}{|c|}{$\begin{array}{l}\text { Concentrado } \\
\text { Concentrate }\end{array}$} & \multicolumn{2}{|c|}{$\begin{array}{l}\text { Teor protéico } \\
\text { Protein content }\end{array}$} & \multicolumn{2}{|c|}{$\begin{array}{c}\text { Monensina } \\
\text { Monensin }\end{array}$} \\
\hline & $\begin{array}{c}\text { Sem } \\
\text { Without }\end{array}$ & $\begin{array}{l}\text { Com } \\
\text { With }\end{array}$ & $\begin{array}{l}\text { Baixo } \\
\text { Low }\end{array}$ & $\begin{array}{l}\text { Alto } \\
\text { High }\end{array}$ & $\begin{array}{c}\text { Sem } \\
\text { Without }\end{array}$ & $\begin{array}{l}\text { Com } \\
\text { With }\end{array}$ \\
\hline MS (kg MS/animal/dia) (DM, $\mathrm{kg}$ DM/animal/day) & $0,84 b$ & $1,27 \mathrm{a}$ & 1,29 & 1,24 & $1,35 \mathrm{a}$ & $1,18 \mathrm{~b}$ \\
\hline MS (kg MS/100kgPV) (DM, $\mathrm{kg} \mathrm{DM/100} \mathrm{kg} \mathrm{BW)}$ & $1,75 b$ & $2,66 \mathrm{a}$ & 2,66 & 2,65 & $2,79 \mathrm{a}$ & $2,52 b$ \\
\hline $\mathrm{MS}\left(\mathrm{g} \mathrm{MS} / \mathrm{PV}^{0,75}\right)\left(D M, g D M / B W^{0.75}\right)$ & $45,80 \mathrm{~b}$ & $69,36 a$ & 69,92 & 68,81 & $73,33 \mathrm{a}$ & $65,40 \mathrm{~b}$ \\
\hline $\mathrm{MO}(\mathrm{g} / \mathrm{dia})(O M, \mathrm{~g} /$ day $)$ & $795,33 b$ & $1.200,18 \mathrm{a}$ & $1.227,77$ & $1.172,60$ & $1.280,28 \mathrm{a}$ & $1.120,09 b$ \\
\hline $\mathrm{PB}(\mathrm{g} / \mathrm{dia})(C P, \mathrm{~g} /$ day $)$ & $69,93 b$ & $184,42 \mathrm{a}$ & $149,58 b$ & $219,26 a$ & $200,22 \mathrm{a}$ & $168,62 b$ \\
\hline $\mathrm{EE}(\mathrm{g} / \mathrm{dia})(E E, g / d a y)$ & $8,05 b$ & $25,66 \mathrm{a}$ & $29,15 \mathrm{a}$ & $22,16 b$ & $27,70 \mathrm{a}$ & $23,61 b$ \\
\hline $\mathrm{CT}(\mathrm{g} / \mathrm{dia})(T C, \mathrm{~g} /$ day $)$ & $717,35 b$ & $990,10 \mathrm{a}$ & $1.049,03 \mathrm{a}$ & $931,18 b$ & $1.052,35 \mathrm{a}$ & $927,85 b$ \\
\hline FDN (g/dia) $(N D F, g / d a y)$ & 653,00 & 660,07 & 674,80 & 645,34 & $695,77 \mathrm{a}$ & $624,37 b$ \\
\hline NDT (g/dia) $(T D N$, g/day $)$ & $388,60 \mathrm{~b}$ & $800,05 \mathrm{a}$ & 814,81 & 785,30 & $857,96 a$ & $742,14 b$ \\
\hline
\end{tabular}

Médias com letras diferentes na mesma linha, dentro de cada fator, indicam diferenças significativas a $5 \%$ pelo teste $\mathrm{F}$.

Means with different letters in the same row, within each factor, differ at $5 \%$ of probability by F test.

Galloway et al. (1993), Zinn \& Borques (1993) e Zinn et al. (1994) também não observaram alterações no consumo de MS quando a monensina foi fornecida aos animais. Outros autores (Su et al., 1993; Su \& Yan, 1997; Garcia et al., 2000; Ruiz et al., 2001), de modo semelhante, também verificaram que o consumo de alimento (MS) não foi alterado quando a monensina foi fornecida a cabritos mestiços (Nubian $\mathrm{x}$ Taiwan), cabras nativas de Taiwan, cordeiros fistulados no rúmen e vacas leiteiras, respectivamente. No entanto, Araújo \& Fernandez (1991) observaram que o fornecimento de monensina (120 mg/kg) a novilhos cruzados (Holandês x Brahma) alimentados com dietas com baixo e alto teor de fibra promoveu diminuição no consumo de MS, independentemente do teor de fibra da dieta. Reduções significativas no consumo de MS com a inclusão de monensina foram observadas por Faulkner et al. (1985), Lee et al. (1990) e Singh \& Mohini (1999) em bovinos, cabritos e bezerros, respectivamente. Patil \& Honmode (1994), no entanto, ao fornecerem monensina $(0,11$ e $22 \mathrm{mg} / \mathrm{kg})$ a cordeiros Malpura em pastejo com suplementação com concentrado, verificaram que o consumo de concentrado diminuiu linearmente $(\mathrm{P}<0,01)$, enquanto o de volumoso (MS) aumentou significativamente com o aumento da proporção de monensina.

Além da mudança nos produtos finais da fermentação ruminal, parte da melhora no desempenho de bovinos em confinamento quando se utilizam ionóforos tem sido atribuída ao aumento da digestibilidade das dietas oferecidas aos animais (Wedegaertner \& Johnson, 1983). Segundo Spears (1990), o fornecimento de monensina promove aumento na digestibilidade aparente da energia e do nitrogênio e na absorção de magnésio, fósforo, zinco e selênio; porém, a digestibilidade da fibra e do amido e as absorções de cálcio, potássio e sódio não têm sido melhoradas com a adição de ionóforos na dieta. Bedo et al. (1990), ao fornecerem monensina a ovinos alimentados com dietas formuladas com diferentes proporções de feno e concentrado, relataram que a eficiência da monensina na melhora da digestibilidade é variável e inconsistente.

Muitos autores (Lee et al., 1990; McCann et al., 1990; Araújo \& Fernandez, 1991; Su et al., 1993; Poti \& Bedo, 1994; Salles \& Lucci, 2000; Plaizier et al., 2000) têm comprovado melhora na digestibilidade, em diferentes graus e de diversos nutrientes, quando a monensina é oferecida a ruminantes. Entretanto, neste experimento, a monensina não influenciou a digestibilidade de nenhum dos nutrientes avaliados (MS, MO, PB, EE, CT e FND). Esses resultados indicam que, apesar da diminuição no consumo de MS nos animais alimentados com a dieta contendo monensina, a taxa de passagem possivelmente não sofreu alteração significativa, o que está relacionado à relação volumoso:concentrado utilizada neste ensaio, de 65:35 respectivamente, na MS.

O nível de proteína também não influenciou a digestibilidade dos nutrientes, exceto as digestibilidades de $\mathrm{PB}$ e EE, que foram maiores nos animais alimentados com as dietas com alto e baixo teor protéico, respectivamente. Também não foi verificada interação teor protéico $\times$ monensina. Os animais que receberam somente feno de capim-braquiária apresentaram menor digestibilidade de MS, MO, PB, EE e NDT, porém tiveram digestibilidade semelhante de FDN (Tabelas 5 e 6).

Zinn \& Borques (1993) e Zinn et al. (1994) forneceram monensina a bovinos em confinamento e também não observaram alterações na digestibilidade de MO, fibra, amido e nitrogênio. Analogamente, Marounek et al. (1989), ao fornecerem monensina a bezerros no período da $3 \underline{a}$ à 10 a semana 


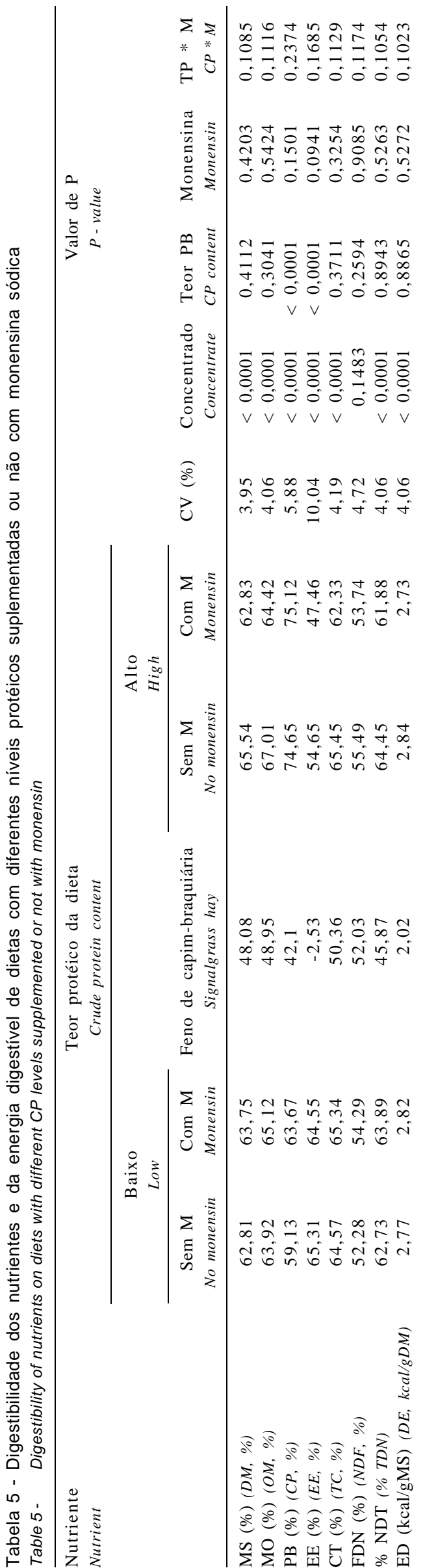

de idade alimentados com leite mais concentrado e feno à vontade, observaram, com exceção dos lipídios, que as digestibilidades da MS, MO, PB e ENN (extrativos nãonitrogenados) não foram influenciadas pela monensina. Outros autores (Faulkner et al., 1985; Rogers et al., 1991; Galloway et al., 1993; Patil \& Honmode, 1994; Singh \& Mohini, 1999; Soodeen \& Youssef, 1999; Garcia et al., 2000; Vikram et al., 2001) também não verificaram mudanças significativas na digestibilidade com o fornecimento de monensina a animais ruminantes.

Segundo McGuffey et al. (2001), o fornecimento de monensina a bovinos promove melhor aproveitamento do nitrogênio dietético, como resultado do menor consumo de MS e da conseqüente redução da ingestão de nitrogênio e diminuição na fermentação de peptídeos e aminoácidos no rúmen, em virtude da menor deaminação e do aumento desses peptídeos e aminoácidos em nível intestinal, causando aumento na digestibilidade do nitrogênio. Neste experimento, o fornecimento de monensina promoveu redução significativa no consumo de nitrogênio e diminuição das perdas de nitrogênio nas fezes; todavia, as perdas pela urina foram semelhantes (Tabelas 7 e 8). O balanço de nitrogênio indicou que a retenção foi maior nos animais alimentados com a dieta sem monensina.

Esses resultados revelam que, nos animais que receberam monensina, possivelmente houve aumento na concentração ruminal de ácido propiônico e, em nível metabólico, redução da degradação dos aminoácidos gliconeogênicos (glutamina, alanina e glicina) para a síntese de glicose. Desse modo, o processo de gliconeogênese foi mantido pelo maior aporte hepático de Succinil CoA, via elevação dos níveis de propionato. Como os animais eram adultos e nesses animais a taxa de deposição muscular é menor, possivelmente parte dos aminoácidos foi degradada a amônia no fígado, ocasionando formação de uréia e aumento da excreção urinária. Por outro lado, os animais alimentados com a dieta sem monensina tiveram maior consumo de nitrogênio (reflexo da maior ingestão de alimentos) e maior perda fecal de aminoácidos. Uma vez que possivelmente essas dietas proporcionaram menor concentração ruminal de ácido propiônico, parte dos aminoácidos absorvidos foi utilizada para síntese de glicose, com conseqüente diminuição do nitrogênio excretado na urina. Esses parâmetros, apesar de não terem sido medidos, foram evidenciados em outros trabalhos (Ørskov et al., 1979; Byers, 1980; Schelling, 1984; Sauer et al., 1998; Maas et al., 2001; Tedeschi, 2003; Ipharraguerre \& Clark, 2003).

Neste ensaio, a dieta com alto teor protéico promoveu consumo de nitrogênio significativamente maior e maior perda de nitrogênio pela urina, o que, possivelmente, está 
Tabela 6 - Digestibilidade dos nutrientes e da energia digestível de dietas com diferentes níveis protéicos suplementadas ou não com monensina

Table 6 - Digetibility of nutrients and digestible energy on diets with different CP levels supplemented or not with monensin

\begin{tabular}{|c|c|c|c|c|c|c|}
\hline \multirow[t]{2}{*}{$\begin{array}{l}\text { Nutriente } \\
\text { Nutrient }\end{array}$} & \multicolumn{2}{|c|}{$\begin{array}{l}\text { Concentrado } \\
\text { Concentrate }\end{array}$} & \multicolumn{2}{|c|}{$\begin{array}{l}\text { Teor protéico } \\
\text { Protein content }\end{array}$} & \multicolumn{2}{|c|}{$\begin{array}{l}\text { Monensina } \\
\text { Monensin }\end{array}$} \\
\hline & $\begin{array}{c}\text { Sem } \\
\text { Without }\end{array}$ & $\begin{array}{l}\text { Com } \\
\text { With }\end{array}$ & $\begin{array}{l}\text { Baixo } \\
\text { Low }\end{array}$ & $\begin{array}{l}\text { Alto } \\
\text { High }\end{array}$ & $\begin{array}{c}\text { Sem } \\
\text { Without }\end{array}$ & $\begin{array}{l}\text { Com } \\
\text { With }\end{array}$ \\
\hline $\operatorname{MS}(\%)(D M, \%)$ & $48,08 \mathrm{~b}$ & $63,73 \mathrm{a}$ & 63,28 & 64,18 & 64,18 & 63,29 \\
\hline $\mathrm{MO}(\%)(O M, \%)$ & $48,95 \mathrm{~b}$ & $65,12 \mathrm{a}$ & 64,52 & 65,71 & 65,47 & 64,77 \\
\hline $\mathrm{PB}(\%)(C P, \%)$ & $42,61 \mathrm{~b}$ & $68,14 \mathrm{a}$ & $61,40 \mathrm{~b}$ & $74,88 \mathrm{a}$ & 66,89 & 69,39 \\
\hline $\mathrm{EE}(\%)(E E, \%)$ & $-2,53 b$ & $57,99 \mathrm{a}$ & $64,93 \mathrm{a}$ & $51,06 \mathrm{~b}$ & 59,98 & 56,01 \\
\hline $\mathrm{CT}(\%)(T C, \%)$ & $50,36 \mathrm{~b}$ & $64,42 \mathrm{a}$ & 64,95 & 63,89 & 65,01 & 63,84 \\
\hline FDN $(\%)(N D F, \%)$ & 52,03 & 53,95 & 53,29 & 54,61 & 53,88 & 54,02 \\
\hline$\%$ NDT (\% TDN) & $45,87 \mathrm{~b}$ & $63,24 \mathrm{a}$ & 63,31 & 63,16 & 63,59 & 62,89 \\
\hline ED (kcal/g MS) (DE, kcal/grams DM) & $2,02 b$ & $2,79 \mathrm{a}$ & 2,79 & 2,78 & 2,80 & 2,77 \\
\hline
\end{tabular}

Médias com letras diferentes na mesma linha, dentro de cada fator, indicam diferenças significativas a $5 \%$ pelo teste $\mathrm{F}$.

Means with different letters in the same row, within each factor, differ at $5 \%$ of probability by $F$ test.

Tabela 7- Consumo de nitrogênio (CN), excreção fecal de nitrogênio (EFN), excreção urinária de nitrogênio (EUN) e balanço de nitrogênio (BN), em g/dia, em ovinos alimentados com dietas com diferentes níveis protéicos suplementadas ou não com monensina

Table 7 - Nitrogen intake (NI), fecal excretion of nitrogen (FEN), urinary excretion of nitrogen (UEN) and nitrogen balance (NB), in grams/day, on diets with different crude protein levels supplemented or not with monensin

\begin{tabular}{|c|c|c|c|c|c|c|c|c|c|}
\hline \multirow[t]{4}{*}{$\begin{array}{l}\text { Nutriente } \\
\text { Nutrient }\end{array}$} & \multicolumn{4}{|c|}{$\begin{array}{l}\text { Teor protéico da dieta } \\
\text { Crude protein content }\end{array}$} & \multirow[b]{4}{*}{$\begin{array}{c}\text { Feno de capim-braquiária } \\
\text { Signalgrass hay }\end{array}$} & \multicolumn{4}{|c|}{$\begin{array}{l}\text { Valor de } \mathrm{P} \\
P \text { - value }\end{array}$} \\
\hline & \multirow{2}{*}{\multicolumn{2}{|c|}{$\begin{array}{l}\text { Baixo } \\
\text { Low }\end{array}$}} & \multirow{2}{*}{\multicolumn{2}{|c|}{$\begin{array}{l}\text { Alto } \\
\text { High }\end{array}$}} & & \multirow[b]{3}{*}{$\begin{array}{l}\text { Concentrado } \\
\text { Concentrate }\end{array}$} & \multirow[b]{3}{*}{$\begin{array}{l}\text { Teor } \mathrm{PB} \\
C P \text { content }\end{array}$} & \multirow[b]{3}{*}{$\begin{array}{l}\text { Monensina } \\
\text { Monensin }\end{array}$} & \multirow[b]{3}{*}{$\begin{array}{r}\mathrm{TP} * \mathrm{M} \\
C P * M\end{array}$} \\
\hline & & & & & & & & & \\
\hline & $\begin{array}{c}\text { Sem M } \\
\text { No monensin }\end{array}$ & $\begin{array}{c}\text { Com M } \\
\text { Monensin }\end{array}$ & $\begin{array}{c}\text { Sem M } \\
\text { No monensin }\end{array}$ & $\begin{array}{c}\text { Com M } \\
\text { Monensin }\end{array}$ & & & & & \\
\hline $\mathrm{CN}(N I)$ & 22,69 & 20,34 & 34,50 & 27,78 & 10,59 & $<0,0001$ & $<0,0001$ & 0,0054 & 0,1325 \\
\hline EFN (FEN) & 9,98 & 7,86 & 9,35 & 7,42 & 6,19 & $<0,0001$ & 0,3081 & 0,0012 & 0,8568 \\
\hline EU (UEN) & 10,55 & 12,53 & 22,68 & 19,89 & 6,19 & $<0,0001$ & $<0,0001$ & 0,7416 & 0,0657 \\
\hline $\mathrm{BN}(N B)$ & 2,17 & $-0,04$ & 2,47 & 0,47 & $-1,80$ & 0,0052 & 0,6364 & 0,0255 & 0,9032 \\
\hline
\end{tabular}

Tabela 8 - Consumo de nitrogênio (CN), excreção fecal de nitrogênio (EFN), excreção urinária de nitrogênio (EUN) e balanço de nitrogênio (BN) em ovinos alimentados com dietas com diferentes níveis protéicos suplementadas ou não com monensina sódica

Table 8 - Nitrogen intake (NI), fecal excretion of nitrogen (FEN), urinary excretion of nitrogen (UEN) and nitrogen balance (NB) on diets with different crude protein levels supplemented or not with monensin

\begin{tabular}{|c|c|c|c|c|c|c|}
\hline \multirow[t]{2}{*}{$\begin{array}{l}\text { Variável } \\
\text { Item }\end{array}$} & \multicolumn{2}{|c|}{$\begin{array}{c}\text { Concentrado } \\
\text { Concentrate }\end{array}$} & \multicolumn{2}{|c|}{$\begin{array}{c}\text { Teor protéico } \\
\text { Protein content }\end{array}$} & \multicolumn{2}{|c|}{$\begin{array}{c}\text { Monensina } \\
\text { Monensin }\end{array}$} \\
\hline & $\begin{array}{c}\text { Sem } \\
\text { Without }\end{array}$ & $\begin{array}{l}\text { Com } \\
\text { With }\end{array}$ & $\begin{array}{l}\text { Baixo } \\
\text { Low }\end{array}$ & $\begin{array}{l}\text { Alto } \\
\text { High }\end{array}$ & $\begin{array}{c}\text { Sem } \\
\text { Without }\end{array}$ & $\begin{array}{l}\text { Com } \\
\text { With }\end{array}$ \\
\hline $\mathrm{CN}(N I)$ & $10,59 b$ & $26,33 \mathrm{a}$ & $21,52 b$ & $31,14 \mathrm{a}$ & $28,60 \mathrm{a}$ & $24,06 \mathrm{~b}$ \\
\hline EFN (FEN) & $6,19 b$ & $8,65 \mathrm{a}$ & 8,92 & 8,38 & $9,66 \mathrm{a}$ & $7,64 b$ \\
\hline EU (UEN) & $6,19 b$ & $16,41 \mathrm{a}$ & $11,54 \mathrm{~b}$ & $21,29 \mathrm{a}$ & 16,61 & 16,21 \\
\hline $\mathrm{BN}(N B)$ & $-1,80 \mathrm{~b}$ & $1,27 \mathrm{a}$ & 1,06 & 1,47 & $2,32 \mathrm{a}$ & $0,21 \mathrm{~b}$ \\
\hline
\end{tabular}

Médias com letras diferentes na mesma linha, dentro de cada fator, diferem a $5 \%$ pelo teste $\mathrm{F}$.

Means with different letters in the same row, within each factor, differ at $5 \%$ of probability by the $F$ test.

relacionado ao excesso de nitrogênio amoniacal no rúmen e de uréia no tecido hepático, com consequiente redução da reciclagem de nitrogênio salivar e eliminação do nitrogênio em excesso pelos rins, por meio da urina. Os animais que receberam somente feno de capim-braquiária apresentaram menor consumo de nitrogênio e menores perdas de nitrogênio nas fezes e na urina e balanço de nitrogênio negativo (Tabelas 7 e 8 ).
Gado (1997), ao fornecer monensina (0, 20 e $40 \mathrm{mg} /$ cabeça/dia) a cabritos, também verificou menor retenção de nitrogênio nos animais sob suplementação. Lee et al. (1990), no entanto, forneceram a caprinos nativos da Coréia dietas com $80 \%$ do consumo ad libitum, contendo $80 \%$ de concentrado e $20 \%$ de feno triturado + monensina $(0,22$ ou $33 \mathrm{mg} / \mathrm{kg}$ ) e não observaram alteração na retenção de nitrogênio nos animais que receberam monensina na dieta. 
No entanto, Plaizier et al. (2000), ao fornecerem monensina em cápsula de liberação controlada a vacas leiteiras, observaram que, após o parto, a monensina aumentou a digestibilidade aparente do nitrogênio e melhorou o balanço de nitrogênio de -77,8 para -44,9g/dia. Aumento na digestibilidade aparente do nitrogênio e redução na perda de nitrogênio fecal também foram relatados por Ruiz et al. (2001) em estudo no qual forneceram monensina a vacas leiteiras alimentadas com dietas à base de forragem fresca com monensina (350 mg/vaca/dia). Patil \& Honmode (1994), no entanto, ao administrarem monensina $(0,11$ e $22 \mathrm{mg} / \mathrm{kg})$ a cordeiros da raça Malpura em pastejo suplementados com concentrado, verificaram que a retenção de nitrogênio foi maior nos animais que receberam $22 \mathrm{mg}$ de monensina, seguidos daqueles que receberam $11 \mathrm{e} 0 \mathrm{mg}$.

\section{Conclusões}

O fornecimento de monensina a ovinos castrados promoveu diminuição do consumo de nutrientes (MS, PB, EE, CT, FDN e NDT), mas não alterou a digestibilidade. A monensina também reduziu a perda de nitrogênio pelas fezes, no entanto, a maior retenção de nitrogênio foi observada nos animais que não receberam monensina.

A dieta com maior teor protéico proporcionou maior consumo de PB e menor ingestão de EE e CT, mas não influenciou os consumos de MS, FDN e NDT.

A digestibilidade da PB da dieta com alto teor protéico foi superior à daquela com menor teor de proteína, não sendo observadas diferenças na digestibilidade dos demais nutrientes avaliados, à exceção do EE, que foi superior na dieta com baixo teor protéico. A perda de nitrogênio na urina foi maior nos animais alimentados com a dieta com alto teor de proteína, porém, houve influência do teor protéico na retenção de nitrogênio pelo animal.

A dieta contendo apenas feno de capim-braquiária foi menos consumida, apresentou menor digestibilidade e balanço de nitrogênio negativo.

\section{Literatura Citada}

ANDRAE, J.G.; HORN, G.W.; BUCHANAN, D.S. et al. Effect of salt intake in a monensin-containing energy supplement on rumen fermentation of steers grazing wheat pasture. Animal Science Research Report Agricultural Experiment Station, n.P-943, p.145-150, 1995

ANDRIGUETTO, J.M.; PERLY, L.; MINARDI, I. et al. Nutrição animal - As bases e os fundamentos da nutrição animal - Os alimentos. 4 ed. São Paulo: Nobel, 1981. v.1, 395p.

ARAUJO, O.F.; FERNANDEZ, M.C. Efecto en novillos del monensin y el nivel de fibra de la dieta sobre el consumo y la digestibilidad de la materia seca. Revista de la Facultad de Agronomía, v.8, n.2, p.143-153, 1991.
BEDO, S.; BODIS, A.; RAVASZ, I. Improvement of digestibility with monensin? Kraftfutter, v.2, n.2, p.62-66, 1990.

BYERS, F.M. Determining effects of monensin on energy value of corn silage diets for beef cattle by linear semi-log methods. Journal of Animal Science, v.51, n.1, p.158-169, 1980.

CLARY, E.M.; BRANDT JR., R.T.; HARMON, D.L. et al Supplemental fat and ionophores in finishing diets: feedlot performance and ruminal digest kinetics in steers. Journal of Animal Science, v.71, n.11, p.3115-3123, 1993.

DENNIS, S.M.; NAGARAJA, T.G.; DAYTON, A.D. Effect of lasalocid, monensin and thiopeptin on rumen protozoa. Research Veterinary Science, v.41, n.2, p.251-256, 1986.

FAULKNER, D.B.; KLOPFENSTEIN, T.J.; TROTTER, T.N. et al. Monensin effects on digestibility, ruminal protein escape and microbial protein synthesis on high-fiber diets. Journal of Animal Science, v.61, n.3, p.654-660, 1985.

FOX, D.G.; BLACK, J.R. A system for predicting body composition and performance of growing cattle. Journal of Animal Science, v.58, n.3, p.725-739, 1984.

GADO, H. Nutrients utilization and growth performance of Baladi goats kids fed monensin sodium supplemented ration. Egyptian Journal of Nutrition and Feeds, n.Special, p.9198, 1997.

GALlOWAY, D.L.S.; GOETSCH, A.L.; PATIL, A. et al. Feed intake and digestion by Holstein steer calves consuming low-quality grass supplemented with lasalocid or monensin. Canadian Journal of Animal Science, v.73, n.4, p.869-879, 1993.

GALYEAN, M.L.; OWENS, F.N. Effects of monensin on growth, reproduction, and lactation in ruminants. ISI Atlas of Science, Animal and Plant Sciences, v.1, n.1, p.71-75, 1988

GARCIA, C.C.G.; MENDOZA, M.G.D.; GONZALEZ, M.S. et al. Effect of a yeast culture (Saccharomyces cerevisiae) and monensin on ruminal fermentation and digestion in sheep. Animal Feed Science and Technology, v.83, n.2, p.165-170, 2000.

GRANZIN, B.C.; DRYDEN, G.M.L. The effects of monensin on milk production and levels of metabolites in blood and rumen fluid of Holstein-Friesian cows in early lactation. Australian Journal of Experimental Agriculture, v.39, n.8, p.933-940, 1999.

HANEY JR., M.E.; HOEHN, M.M. Monensin, a new biologically active compound. I. Discovery and isolation. Antimicrobial Agents Chemother, v.7, p.349-352, 1967.

HANSON, T.L.; KLOPFENSTEIN, T. Monensin, protein source and protein levels for growing steers. Journal of Animal Science, v.48, n.3, p.474-479, 1979.

IPHARRAGUERRE, I.R; CLARK J.H. Usefulness of ionophores for lactating dairy cows: a review. Animal Feed Science and Technology - Elsevier Science, v.106, n.1, p.39-57, 2003.

KALACHNYUK, G.I.; MAROUNEK, M.; SHIMUNEK, I. et al. Effect of ionophore on volatile fatty acid production in the rumen. Sel'skokhozyaistvennaya Biologiya, n.2, p.93-98, 1990.

LEE, S.K.; LEE, B.D.; JUNG, K.K. et al. Effect of feeding monensin on the feed intake, nutrient utilization and ruminal fermentation of Korean native goat. Korean Journal of Animal Sciences, v.32, n.2, p.74-82, 1990.

MAAS, J.A.; WILSON, G.F.; McCUTCHEON, S.N. The effect of season and monensin sodium on the digestive characteristics of autumn and spring pasture fed to sheep. Journal of Animal Science, v.79, n.4, p.1052-1058, 2001.

MAROUNEK, M.; SKRIVANOVA, V.; MACHANOVA, L. Effect of monensin on digestibility of nutrients, ruminal volatile fatty acids and blood parameters in young calves. Landwirtschaftliche Forschung, v.42, n.4, p.273-280, 1989.

McCANN, M.A.; CRADDOCK, B.F.; PRESTON, R.L. et al. Digestibility of cotton plant by-product diets for sheep at two levels of intake. Journal of Animal Science, v.68, n.2, p.285-295, 1990 .

McGUFFEY, R.K.; RICHARDSON, L.F.; WILKINSON, J.I.D. Ionophores for dairy cattle: current status and future outlook. Journal of Dairy Science, v.84, p.194-203, 2001 (suppl.) 
MACHADO, P.F.; MADEIRA, H.M.F. Manipulação de nutrientes em nível de rúmen - efeitos do uso de ionóforos. Bovinocultura de corte. Piracicaba: Fundação de Estudos Agrários Luiz de Queiroz, 1990. p.79-96.

MAYNARD, L.A.; LOOSLI, J.K.; HINTZ, H.F. et al. Nutrição animal. 3.ed. Rio de Janeiro: Freitas Bastos, 1984. 726p.

MEDEL, M.; MERINO, P.; THOMAS, R. et al. Modo de acción del monensin en metabolismo ruminal y comportamiento animal. Ciencia e Investigación Agraria, v.18, n.3, p.153-173, 1991.

OLIVEIRA, M.V.M.; LANA, R.P.; VALADARES, R.F.D. et al. Parâmetros ruminais e glicose sanguínea em novilhas leiteiras sob dietas com diferentes níveis de monensina. In: REUNIÃO ANUAL DA SOCIEDADE BRASILEIRA DE ZOOTECNIA, 39. 2002, Recife. Anais... São Paulo: Sociedade Brasileira de Zootecnia [2002]. (CD-ROM).

ØRSKOV, E.R.; GRUBB, D.A.; SMITH, J.S. et al. Efficiency of utilization of volatile fatty acids for maintenance and energy retention by sheep. Journal Nutrition, v.41, p.541-552, 1979.

PATIL, N.V.; HONMODE, J. Growth and nutrient utilization in lambs as influenced by dietary monensin. Indian Journal of Animal Nutrition, v.11, n.4, p.237-239, 1994.

PLAIZIER, J.C.; MARTIN, A.; DUFFIELD, T. et al. Effect of a prepartum administration of monensin in a controlled-release capsule on apparent digestibilities and nitrogen utilization in transition dairy cows. Journal of Dairy Science, v.83, n.12, p.2918-2925, 2000 .

POTI, P.; BEDO, S. Effect of various growth promoters on dietary nutrient digestibility in sheep. Allattenyesztes es Takarmanyozas, v.43, n.1-2, p.31-40, 1994

ROGERS, M.; JOUANY, J.P.; THIVEND, P. et al. Comparative effects of feeding and duodenal infusion of monensin on digestion in sheep. Canadian Journal of Animal Science, v.71, n.4, p.1125-1133, 1991

RUIZ, R.; ALBRECHT, G.L.; TEDESCHI, L.O. et al. Effect of monensin on the performance and nitrogen utilization of lactating dairy cows consuming fresh forage. Journal of Dairy Science, v.84, n.7, p.1717-1727, 2001

RUSSELL, J.B. Bacteria. "Mechanisms of ionophore action in ruminal bacteria". In: Symposium Sponsored by: Elanco Animal Health. Scientific Update "On rumensin/Tylan/Micotil for the professional feedlot consultant". Symposium... Amarillo, 1996. p.E1-E19.

RUSSELL, J.B.; STROBEL, H.J. Mini review. Effect of ionofores on ruminal fermentation. Applied and Environmental Microbiology, v.55, n.1, p.1-6, 1989.

RUSSELL, J.B.; WALLACE, R.J. Energy-yielding and energyconsuming reactions. In: HOBSON, P.N.; STEWART, C.S. (Eds.) The rumen microbial ecosystem. 2.ed. London: Blackie Academic \& Professional, 1997. p.267-268.

SALLES, M.S.V.; LUCCI, C.S. Monensina para bezerros ruminantes em crescimento acelerado. 2. Digestibilidade e parâmetros ruminais. Revista Brasileira de Zootecnia, v.29, n.2, p.582588,2000

SAUER, F.D.; FELLNER, V.; KINSMAN, R. et al. Methane output and lactation response in Holstein cattle with monensin or unsaturated fat added to the diet. Journal of Animal Science, v.76, p.906-914, 1998

SCHELLING, G.T. Monensin mode of action in the rumen. Journal of Animal Science, v.58, p.1518-1527, 1984.

SCHNEIDER, B.H.; FLATT, W.P. The evaluation of feeds through digestibility experiments. Athens: The University of Georgia Press, 1975. 423p.

SILVA, D.J. Análise de alimentos: métodos químicos e biológicos. 2.ed. Viçosa, MG: Universidade Federal de Viçosa, 1990. 195p.

SILVA, J.F.C.; LEÃO, M.I. Fundamentos de nutrição dos ruminantes. Piracicaba: Livroceres, 1979. 380p.
SINGH, G.P.; MOHINI, M. Effect of different levels of rumensin in diet on rumen fermentation, nutrient digestibility and methane production in cattle. Asian Australasian Journal of Animal Sciences, v.12, n.8, p.1215-1221, 1999.

SNIFFEN, C.J.; O'CONNOR, J.D.; Van SOEST, P.J. et al. A net carbohydrate and protein system for evaluating cattle diets. II. Carbohydrate and protein availability. Journal of Animal Science, v.70, n.11, p.3562-3577, 1992.

SOODEEN, K.S.; YOUSSEF, F.G. Effect of monensin, avoparcin and grass supplementation on utilization of urea-treated rice straw by sheep and goats. Small Ruminant Research, v.33, n.3, p.201-211, 1999 .

SPEARS, J.W. Ionophores and nutrient digestion and absorption in ruminants. Journal of Nutrition, v.120, n.6, p.632-638, 1990.

STATISTIC ANALYSIS SYSTEM - SAS. User's guide. Cary: 1997. $429 \mathrm{p}$.

SU, A.K.; YAN, S.S. Effect of monensin and urea supplementing levels on the growth performance of hybrid goats. Journal of Taiwan Livestock Research, v.30, n.2, p.151-159, 1997.

SU, A.K.; YAN, S.S.; WU, S.C. Effect of monensin concentration in diets on growth performance and propionate concentration in the rumen of crossbred kids. Journal of Taiwan Livestock Research, v.26, n.4, p.297-306, 1993

TEATHER, R.M.; FORSTER, R.J. Manipulating the rumen microflora with bacteriocins to improve ruminant production. Canadian Journal of Animal Science, v.78, p.57-69, 1998 (suppl.).

TEDESCHI, L.O.; FOX, D.G.; TYLUTKI, T.P. Potential environmental benefits of ionophores in ruminant diets. Journal of Environmental Quality, v.32, n.5, p.1591-1602, 2003.

VIKRAM, C.; RAMACHANDRA, B.; NAGABHUSHAN, V. et al. Effect of supplementation of monensin sodium on nutrient utilization in Deoni calves. Indian Veterinary Journal, v.78, n.7, p.611-614, 2001

WARD, M.G.; ADAMS, D.C.; WALLACE, J.D. et al. Supplementation and monensin effects on digest kinetics. 1. Cattle grazing summer range. Journal of Range Management, v.43, n.5, p.378-382, 1990a

WARD, M.G.; ADAMS, D.C.; WALLACE, J.D. et al. Supplementation and monensin effects on digesta kinetics. 2. Cattle grazing winter range. Journal of Range Management, v.43, n.5, p.383-386, 1990b.

WEDEGAERTNER, T.C.; JOHNSON, D.E. Monensin effects on digestibility, methanogenesis and heat increment of a cracked corn-silage diet fed to steers. Journal of Animal Science, v. 57, p. $168-177,1983$

YANG, C.M.J.; RUSSELL, J.B. The effect of monensin supplementation on ruminal ammonia accumulation in vivo and the numbers of amino acid-fermenting bacteria. Journal of Animal Science, v.71, n.12, p.3470-3476, 1993.

ZINN, R.A.; BORQUES, J.L. Influence of sodium bicarbonate and monensin on utilization of a fat-supplemented, high-energy growing-finishing diet by feedlot steers. Journal of Animal Science, v.71, n.1, p.18-25, 1993.

ZINN, R.A.; PLASCENCIA, A.; BARAJAS, R. Interaction of forage level and monensin in diets for feedlot cattle on growth performance and digestive function. Journal of Animal Science, v.72, n.9, p.2209-2215, 1994. 